07.2

\title{
Влияние температуры протонного облучения на характеристики мощных высоковольтных карбид-кремниевых диодов Шоттки
}

\author{
(c) В.В. Козловский ${ }^{1}$, О. Корольков ${ }^{2}$, К.С. Давыдовская ${ }^{3}$, А.А. Лебедев ${ }^{3}$, М.Е. Левинштейн ${ }^{3}$, Н. Слепчук ${ }^{2}$, \\ А.М. Стрельчук ${ }^{3}$, J. Тоотрии ${ }^{2}$ \\ ${ }^{1}$ Санкт-Петербургский политехнический университет Петра Великого, Санкт-Петербург, Россия \\ ${ }^{2}$ Tallinn University of Technology, Tallinn, Estonia \\ ${ }^{3}$ Физико-технический институт им. А.Ф. Иофрфе РАН, Санкт-Петербург, Россия \\ E-mail: kozlovski@physics.spbstu.ru
}

Поступило в Редакцию 14 октября 2019 г.

В окончательной редакции 14 октября 2019 г.

Принято к публикации 19 декабря 2019г.

\begin{abstract}
Впервые исследовано влияние облучения при высокой температуре („горячего облучения“) протонами на вольт-фарадные и вольт-амперные характеристики полупроводниковых приборов на основе карбида кремния. Исследовались коммерческие высоковольтные (блокирующее напряжение $1700 \mathrm{~V}$ ) интегрированные $4 \mathrm{H}$-SiC-диоды Шоттки. Облучение производилось протонами с энергией $15 \mathrm{MeV}$ при температурах $20-400^{\circ} \mathrm{C}$. Установлено, что наиболее чувствительным к облучению параметром, определяющим радиационную стойкость приборов, является омическое сопротивление базы, монотонно возрастающее с ростом дозы облучения $D$. Показано, что при „горячем“ облучении радиационная стойкость диодов существенно превышает стойкость диодов при низкотемпературном („холодном“) облучении. Сделан вывод, что с ростом температуры облучения уменьшается скорость образования глубоких центров в верхней половине запрещенной зоны карбида кремния.
\end{abstract}

Ключевые слова: карбид кремния, диод Шоттки, протонное облучение, радиационные дефекты.

DOI: 10.21883/PJTF.2020.06.49163.18072

Мощные высоковольтные карбид-кремниевые диоды Шоттки стали в последние годы одним из важнейших элементов высокотемпературной и радиационно стойкой электроники. Радиационная стойкость полупроводниковых приборов по отношению к различным типам облучения часто является параметром, определяющим возможность применения прибора, особенно в таких приложениях, как космическая электроника и работа в электронных системах ядерных реакторов. Исследованию влияния различных типов излучения, включая облучение протонами при комнатной температуре („холодное“ протонное облучение), на свойства $4 H-\mathrm{SiC}$ и приборов на его основе посвящено довольно много публикаций (см., например, [1-8]). В настоящей работе впервые исследовано одновременное воздействие протонного облучения и повышенной температуры („горячее“ протонное облучение) на полупроводниковые приборы на основе карбида кремния на примере высоковольтных интегрированных диодов Шоттки.

В ходе работы проводилось облучение коммерческих диодов Шоттки производства компании CREE (CPW3-1700SO10) [9]. Исходная концентрация нескомпенсированной примеси $\left(N_{d}-N_{a}\right)$ в $n$-базе диодов Шоттки составляет $\sim(3-4) \cdot 10^{15} \mathrm{~cm}^{-3}$.

Приборы облучались протонами с энергией $15 \mathrm{MeV}$ на малогабаритном циклотроне MGTs-20 [10]. Для измерения параметров диодов использовались LEMSYS DMS dynamic parametersystem, KEITHLEY SourceMeter 2400 и KEITHLEY 6485 picoammeter. Для облучения отби- рались диоды, характеризующиеся близкой к идеальной $I-V$-характеристикой при прямом смещении, а именно экспоненциальной (до области влияния последовательного сопротивления диода) прямой вольт-амперной характеристикой $I=I_{0} \exp (q U / \beta k T)$ с коэффициентом идеальности $\beta \approx 1.02-1.04$ и током утечки при малых обратных напряжениях $\sim 10^{-13}-10^{-12}$ А. Здесь $q-$ элементарный заряд, $k-$ постоянная Больцмана.

Эксперимент показывает, что облучение во всем исследованном температурном диапазоне весьма слабо влияет на зависимость прямого тока от напряжения на экспоненциальном участке зависимости вольт-амперной характеристики. Для облучения при комнатной температуре такой результат наблюдался ранее в работе [11].

На рис. 1 показаны вольт-амперные характеристики диодов при больших прямых смещениях, когда бо́льшая часть приложенного напряжения падает на базе прибора (квазилинейные вольт-амперные характеристики).

Как видно из рисунка, в области больших прямых смещений холодное облучение (кривая 4) приводит к существенному возрастанию дифференциального сопротивления базы $R_{s}$. При исходном значении $R_{s} \sim 0.3 \Omega$ (при токе $1 \mathrm{~A}$ ) после облучения при комнатной температуре дозой $D=4 \cdot 10^{13} \mathrm{~cm}^{-2}$ значение $R_{s}$ увеличивается приблизительно в 2.5 раза до $\sim 0.75 \Omega$.

Поскольку изменение концентрации в $\sim 2.5$ раза при исходной концентрации $\sim 4 \cdot 10^{15} \mathrm{~cm}^{-3}$ не приводит к сколько-нибудь заметному изменению подвижности электронов [12], очевидно, что рост сопротивления базы 


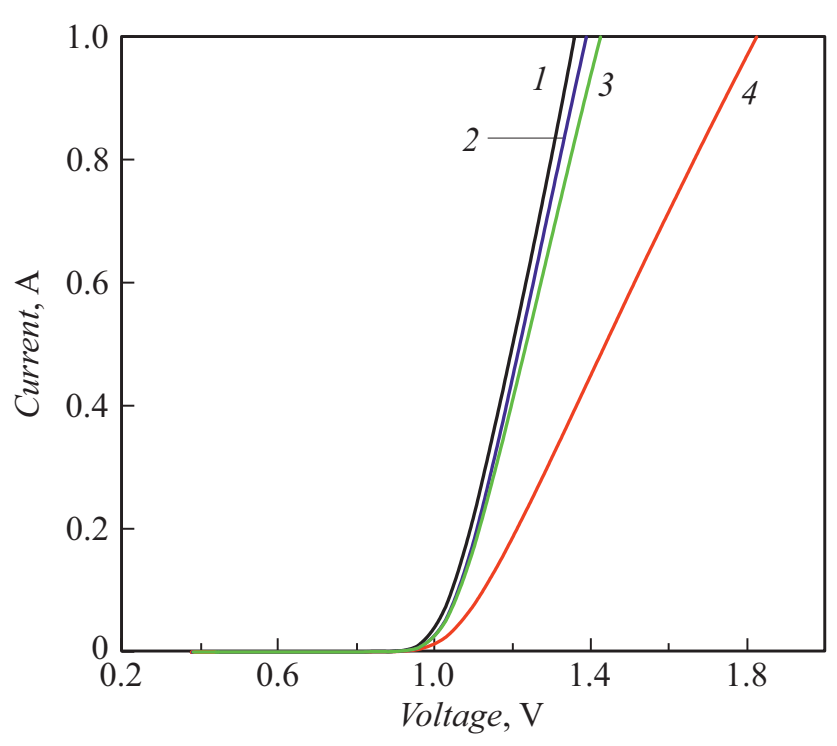

Рис. 1. Прямые вольт-амперные характеристики диодов в области больших прямых напряжений до (1) и после $(2-4)$ облучения протонами с энергией $15 \mathrm{MeV}$ при температурах облучения $\Theta=400(2), 300(3)$ и $20^{\circ} \mathrm{C}(4)$. Доза $D=4 \cdot 10^{13} \mathrm{~cm}^{-2}$.

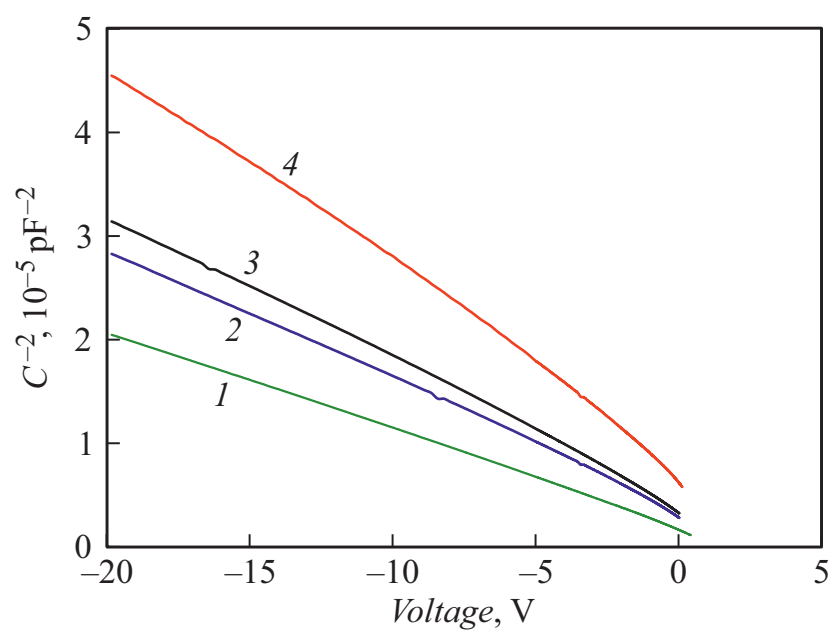

Рис. 2. Обратные вольт-фарадные характеристики диодов до (1) и после $(2-4)$ облучения протонами с энергией $15 \mathrm{MeV}$ при температурах облучения $\Theta=400$ (2), 300 (3) и $20^{\circ} \mathrm{C}(4)$.

происходит за счет захвата свободных электронов на уровни радиационных дефектов, созданных протонным облучением.

Скорость удаления электронов $\eta_{e}$, оцениваемая по стандартной формуле $\eta_{e}=\left(n_{0}-n\right) / D$, для $\Theta=20^{\circ} \mathrm{C}$ составляет $\sim 50 \mathrm{~cm}^{-1}$. Это значение хорошо согласуется с величинами $\eta_{e}$, установленными для комнатной температуры облучения ранее (см., например, [13]).

Для горячего облучения (кривые 2 и 3 на рис. 1) значения $R_{s}$ после облучения дозой $D=4 \cdot 10^{13} \mathrm{~cm}^{-2}$ составляют 0.37 и $0.33 \Omega$ для температур 300 и $400^{\circ} \mathrm{C}$ соответственно. Таким образом, значение $\eta_{e}$ составляет $\sim 13 \mathrm{~cm}^{-1}$ для $\Theta=300^{\circ} \mathrm{C}$ и $\sim 9 \mathrm{~cm}^{-1}$ для $\Theta=400^{\circ} \mathrm{C}$.
На рис. 2 показаны вольт-фарадные $(C-V)$ характеристики диодов, измеренные при обратном смещении после облучения при различных температурах $\Theta$.

Оцененные из показанных на рис. 2 зависимостей $C^{-2}(V)$ значения концентрации нескомпенсированных доноров $\left(N_{d}-N_{a}\right)$ и скорости удаления свободных электронов из зоны проводимости $\eta_{d}$ близки к величинам, полученным при анализе прямых вольт-амперных характеристик (рис. 1).

Механизм образования радиационных дефектов (РД) в $n$-SiC при холодном протонном облучении изучен довольно подробно. Основные РД, обусловливающие компенсацию проводимости, связаны с компонентами пары Френкеля (ПФ) - вакансия и междоузельный атом - только в одной из подрешеток $\mathrm{SiC}$, а именно в углеродной. При холодном протонном облучении около 25\% первичных ПФ избегают рекомбинации и разделяются на отдельные компоненты, входящие в состав известных дефектов Z1/Z2 и ЕН6/7, создающих в запрещенной зоне $n$-SiC глубокие акцепторные уровни $E_{c}-0.65 \mathrm{eV}$ и $E_{c}-1.55 \mathrm{eV}$ соответственно $[11,14]$. Захват электронов на эти уровни приводит к росту удельного сопротивления базы.

Как отмечалось выше, в настоящей работе впервые исследованы эффекты, связанные с дефектообразованием в карбиде кремния при горячем облучении. Однако опыт исследования эффектов, обусловленных горячим облучением в материалах $\mathrm{A}_{3} \mathrm{~B}_{5}$ [15], позволяет предположить два возможных сценария, объясняющих эффекты горячего облучения.

В первом варианте спектр вторичных РД не изменяется по отношению к холодному облучению. В этом случае с ростом температуры облучения просто уменьшается доля первичных ПФ, которые диссоциируют на отдельные компоненты и создают дефекты Z1/Z2 и EH6/7, компенсирующие проводимость $n$-SiC. Сделанные выше оценки показывают, что для температуры облучения $400^{\circ} \mathrm{C}$ эта доля составляет порядка $10 \%$, т.е. в 2.5 раза меньше, чем при облучении при комнатной температуре.

Второй сценарий предполагает, что при высокой температуре облучения полностью изменяется спектр создаваемых вторичных РД. Такой эффект ранее наблюдался при горячем электронном облучении GaAs и InP [15].

Важно отметить, что, поскольку скорость генерации первичных РД в полупроводнике практически не зависит от уровня его легирования [16], полученные результаты представляют интерес для широкого класса приборов на основе $\mathrm{SiC}$.

Таким образом, впервые показано, что при облучении карбида кремния протонами с ростом температуры скорость удаления носителей из зоны проводимости существенно уменьшается. Уменьшение скорости образования центров компенсации с повышением температуры облучения может быть связано с уменьшением концентрации тех же РД, которые создаются при холодном облучении. Возможно также кардинальное изменение спектра создаваемых вторичных РД. 


\section{Финансирование работы}

Работа выполнена при частичной поддержке Российского научного фонда (проект № 16-12-10106). Исследование поддержано также Estonian Research Council в рамках Institutional Research Project IUT19-11 и Horizon 2020 ERA-chair Grant „Cognitive Electronics COEL“ H2020-WIDESPREAD-2014-2 (agreement number 668995; project TTU code VFP15051) и TAR16013 Center of Excellence „EXCITE IT“, а также IT Academy Program of Information Technology Foundation for Education.

\section{Конфликт интересов}

Авторы заявляют, что у них нет конфликта интересов.

\section{Список литературы}

[1] Iwamoto N., Svensson B.G. Point defects in silicon carbide // Defects in semiconductors / Eds L. Romano, V. Privitera, Ch. Jagadish. Ser. Semiconductors and Semimetals. V. 91. Elsevier, 2015. Ch. 10. P. 369.

[2] Лебедев А.А., Никитина И.П., Середова Н.В., Полетаев Н.К., Лебедев С.П., Козловский В.В., Зубов А.В. // Письма в ЖТФ. 2019. Т. 45. В. 11. С. 28-30.

[3] Emtsev V.V., Davydov V.Yu., Goncharuk I.N., Kozlovski V.V., Kalinina E.V., Poloskin D.S., Sakharov A.V., Shmidt N.M., Smirnov A.N., Usikov A.S. // Mater. Sci. Forum. 1997. V. 258-263. P. 1143-1148.

[4] Лебедев А.А., Вейнгер А.И., Давыдов Д.В., Савкина Н.С., Стрельчук А.М., Козловский В.В. // ФТП. 2000. Т. 34. В. 8. C. 897-902.

[5] Kozlovski V.V., Lebedev A.A., Levinshtein M.E., Rumyantsev S.L., Palmour J.W. // Appl. Phys. Lett. 2017. V. 110. P. 083503.

[6] Castaldini A., Cavallini A., Rigutti L. // Semicond. Sci. Technol. 2006. V. 21. P. 724-728.

[7] von Bardeleben H.J., Cantin J.L., Vickridge I., Battistig G. // Phys. Rev. B. 2000. V. 62. P. 10126-10134.

[8] Иванов П.А., Кудояров М.Ф., Потапов А.С., Самсонова Т.П. // ФТП. 2019. Т. 53. В. 6. С. 862-864.

[9] https://www.wolfspeed.com/media/downloads/16/CPW31700-S010B.pdf

[10] Zakharenkov L.F., Kozlovski V.V., Shustrov B.A. // Phys. Status Solidi A. 1990. V. 117. P. 85-90.

[11] Kozlovski V.V., Lebedev A.A., Levinshtein M.E., Rumyantsev S.L., Palmour J.W. // J. Appl. Phys. 2018. V. 123. P. 024502.

[12] Properties of advanced semiconductor materials: GaN, AIN, InN, BN, SiC, SiGe / Eds M.E. Levinshtein, S.L. Rumyantsev, M.S. Shur. N.Y.: John Wiley \& Sons, Inc., 2001. 216 p.

[13] Emtsev V.V., Ivanov A.M., Kozlovski V.V., Lebedev A.A., Oganesyan G.A., Strokan N.B., Wagner G. // ФТП. 2012. T. 46. B. 4. C. $473-481$.

[14] Kaneko H., Kimoto T. // Appl. Phys. Lett. 2011. V. 98. P. 262106

[15] Kozlovski V.V., Kolchenko T.I., Lomako V.M., Zakharenkov L.F. // Rad. Eff. Def. Solids. 1996. V. 138. P. 63-73.

[16] Los A.V., Mazzola M.S. // J. Electron. Mater. 2001. V. 30. P. 235-241. 